Saudi Journal of Medicine

Abbreviated Key Title: Saudi J Med ISSN 2518-3389 (Print) |ISSN 2518-3397 (Online) Scholars Middle East Publishers, Dubai, United Arab Emirates Journal homepage: https://saudijournals.com/sjm

Original Research Article

\title{
To Assess the Clinical Features of Hyponatremia in Adult Subjects Admitted in SMS Hospital
}

\author{
Dr. Ajay Kumar ${ }^{1}$, Dr. Vijaiendre Singh ${ }^{1 *}$, Dr. Kamalesh Kumar Bajia ${ }^{1}$, Dr. Chaina Ram ${ }^{1}$, Dr. Rohit Ishran ${ }^{2}$, Dr. S.Banerjee ${ }^{3}$ \\ ${ }^{1}$ Senior Resident, ${ }^{2}$ Assistan Professor, ${ }^{3}$ Senoir Professor, Upgraded Department of Medicine, SMS Medical College and Hospital, Jawahar Lal Nehru \\ Marg, Gangawal Park, Adarsh Nagar, Jaipur, Rajasthan 302004, India
}

\author{
DOI: $\underline{10.36348 / \text { sjm.2020.v05i08.001 }}$ \\ | Received: 22.07.2020 | Accepted: 30.07.2020 | Published: 06.08.2020
}

*Corresponding Author: Dr. Vijaiendre Singh

\section{Abstract}

Background: Hyponatremia, which is defined as plasma sodium concentration of less than $135 \mathrm{meq} / \mathrm{L}$, occurs primarily due to imbalance in water homeostasis, antidiuretic hormone (ADH) regulation and renal handling of filtered sodium. The two most common causes are effective circulating volume depletion causing non-osmotic release of ADH and the syndrome of inappropriate $\mathrm{ADH}$ secretion, disorders in which $\mathrm{ADH}$ secretion is not suppressed despite decrease in plasma osmolality. Methods: Observational Study conducted at Medicine wards and, Medicine OPD of SMS hospital, Jaipur. Patients were interviewed for demographic data such as age and sex. History of other comorbid conditions along with presenting complaints was noted. Further these patients were subjected to a physical examination for clinical signs. These findings were recorded on a predesigned and pretested proforma. Results: In our study, lethargy(50.4\%), headache $(42.3 \%)$ and anxiety $(31.7 \%)$ were most common symptoms. Majority of the cases were admitted and treated in the ward i.e. 249(87.7\%), while few patients were treated in ICU i.e.35 (12.3\%). Conclusion: Based on the findings of this study it may be concluded that, hyponatremia can present with protean clinical manifestations. The presentation can vary from mild symptoms such as vomiting, lethargy, malaise to severe forms such as confusion, seizure and coma.

Keywords: Hyponatremia, vomiting, lethargy.

Copyright @ 2020: This is an open-access article distributed under the terms of the Creative Commons Attribution license which permits unrestricted use, distribution, and reproduction in any medium for non-commercial use (NonCommercial, or CC-BY-NC) provided the original author and source are credited.

\section{INTRODUCTION}

Sodium is the principal extracellular cation and the main salt of osmolality [1]. Majority of the body's sodium is found in blood plasma and other extracellular fluids, $40 \%$ in bone, and remaining $2 \%-5 \%$ in other cells and organs. This asymmetric distribution of sodium is essential for life and aids in nerve conduction, passage of various nutrients into the cell and maintenance of blood pressure. Sodium related disorders (both hyponatremia and hypernatremia) are associated with considerable morbidity and mortality [2].

Hyponatremia is the commonest electrolyte disorder [3], reported in upto $6 \%$ of hospital patients [4]. Mild hyponatremia (plasma sodium 130-135 $\mathrm{mmol} / \mathrm{l}$ ) is found in as many as 15 to $30 \%$ of hospitalized patients. The occurrence and consequences of hyponatremia increases with age. Hyponatremia that is moderate to severe and particularly of rapid onset is often associated with substantial morbidity and mortality [5].
Hyponatremia, which is defined as plasma sodium concentration of less than $135 \mathrm{meq} / \mathrm{L}$, occurs primarily due to imbalance in water homeostasis, antidiuretic hormone $(\mathrm{ADH})$ regulation and renal handling of filtered sodium. The two most common causes are effective circulating volume depletion causing non-osmotic release of ADH and the syndrome of inappropriate $\mathrm{ADH}$ secretion, disorders in which $\mathrm{ADH}$ secretion is not suppressed despite decrease in plasma osmolality [6].

Physical findings are highly variable and dependent on the degree and the chronicity of hyponatremia. Patients could present with variable degrees of cognitive impairment, focal or generalized seizure activity, signs of brainstem herniation including coma; fixed, unilateral, dilated pupil; decorticate or decerebrate posturing; and respiratory arrest [7].

In addition to neurologic findings, patients may exhibit signs of hypovolemia or hypervolemia. Determining the hydration status of the patient may help establish the etiology of the hyponatremia and suggest the best treatment course [7]. 
Dry mucous membranes, tachycardia, diminished skin turgor, and orthostasis suggest hypovolemic hyponatremia which could be due to excessive loss of body fluids and replacement with inappropriately dilute fluids.

Pulmonary rales, S3 gallop, peripheral edema, or ascites suggest hypervolemic hyponatremia due to excess retention of sodium and free water (e.g.cirrhosis of liver, nephrotic syndrome, congestive heart failure) [7].

\section{MATERIAL AND METHODS}

Study Type: Observational Study.

Study Place: Medicine wards and Medicine OPD of SMS hospital, Jaipur.

\section{Duration of Study: One Year Duration}

\section{Sample Size}

The minimum Sample size, required is 284 hyponatremia cases at $95 \%$ confidence interval and $1.4 \% \%$ absolute error to verify the lowest $1.4 \%$ proportion of different etiological factors among hyponatremia patients.

Sampling Method: Consecutive patients

\section{Selection Criteria}

Inclusion Criteria

- $\quad$ Subjects aged $\geq 18$ years with serum sodium < $135 \mathrm{meq} / \mathrm{l}$

\section{Exclusion Criteria}

- Subjects with repeat serum sodium values $>135 \mathrm{meq} / \mathrm{l}$

- Hyperlipidemia.

- Hyperproteinemia.

\section{Method of Collection of Data}

Patients were interviewed for demographic data such as age and sex. History of other comorbid conditions along with presenting complaints was noted. Further these patients were subjected to a physical examination for clinical signs. These findings were recorded on a predesigned and pretested proforma.

\section{Statistical Analysis}

The data obtained was coded and entered into Microsoft Excel Worksheet (Annexure III). The categorical data was expressed as rates, ratios and proportions. The continuous data was expressed as mean \pm standard deviation (SD). The comparison of categorical data was done using Chi-square test or Fisher's exact test and the comparison of continuous data was done using independent sample ' $t$ ' test. A probability value (' $\mathrm{p}$ ' value) of less than or equal to 0.050 at $95 \%$ confidence interval was considered as statistically significant.

\section{RESULTS}

Table-1: Sex distribution of Hyponatremia patients

\begin{tabular}{|l|l|l|}
\hline Sex & $\mathbf{N}$ & Percentage \\
\hline Female & 118 & 41.5 \\
\hline Male & 166 & 58.5 \\
\hline Total & 284 & 100 \\
\hline
\end{tabular}

Total number of cases in our study was 284 , where 166 were males $(58.5 \%)$ and 118 were females $(41.5 \%)$

Table-2: Age distribution of Hyponatremia patients

\begin{tabular}{|l|l|l|}
\hline Age group $($ years $)$ & $\mathbf{N}$ & Percentage \\
\hline$\leq 20$ years & 16 & 5.6 \\
\hline $21-30$ years & 42 & 14.8 \\
\hline $31-40$ years & 45 & 15.8 \\
\hline $41-50$ years & 63 & 22.2 \\
\hline $51-60$ years & 48 & 16.9 \\
\hline $61-70$ years & 44 & 15.5 \\
\hline $71-80$ years & 20 & 7 \\
\hline $81-90$ years & 6 & 2.1 \\
\hline Total & 284 & 100 \\
\hline
\end{tabular}

Mean age of study population was $38.4 \pm$ 11.97 years Mean age of population in our study was $38.4 \pm 11.97$ years. Largest group of cases i.e.63(22.2\%) were in the age group 41-50 years.

Table-3: Distribution of presenting complaints among Hyponatremia patients

\begin{tabular}{|l|l|l|}
\hline Presenting complaints & N & Percentage \\
\hline Headache & 120 & 42.3 \\
\hline Anxiety & 90 & 31.7 \\
\hline Lethargy & 143 & 50.4 \\
\hline Confusion & 31 & 10.9 \\
\hline Disturbed sleep & 51 & 18 \\
\hline Irrelevant speech & 24 & 8.5 \\
\hline Drowsiness & 20 & 7 \\
\hline Seizure & 25 & 8.8 \\
\hline Unresponsiveness & 50 & 17.6 \\
\hline
\end{tabular}

In our study, lethargy $(50.4 \%)$, headache $(42.3 \%)$ and anxiety $(31.7 \%)$ were concluded to be the most common symptoms.

Table-4: Type of care required for Hyponatremia patients

\begin{tabular}{|l|l|l|}
\hline Care & N & Percentage \\
\hline Ward & 249 & 87.7 \\
\hline ICU & 35 & 12.3 \\
\hline Total & 284 & 100 \\
\hline
\end{tabular}

In our study, majority of the cases were admitted and treated in the ward i.e. 249(87.7\%), while few patients were treated in ICU i.e.35(12.3\%). 


\section{DISCUSSION}

Despite being the commonest electrolyte imbalance, hyponatremia remains incompletely understood in many basic areas. Its association with a plethora of underlying disease states, and its multiple etiologies with differing pathophysiological mechanisms makes diagnosis challenging. Hyponatremia is known to increase inpatient mortality and therefore, this study was undertaken as an attempt to describe the clinical profile and to find out etiology among patients with hyponatremia [8].

In our study of 284 patients admitted with hyponatremia slight male preponderance was noted with $58.5 \%$ of patients being male. The male to female ratio was 1.40:1. Similar sex distribution pattern was reported by Rahil AI et al., [8] where 33 (62.3\%) patients with hyponatremia were males and 20 (37.7\%) were females. Similary, in a study done on frequency and etiology of hyponatremia in adults conducted by Thomas Vurgese et al., [9], 56\% were male patients and $44 \%$ were females. However, Hawkins RC et al., [10] in a study concluded that gender is not an important risk factor for disturbances of serum $\mathrm{Na}$ concentration.. In the present study no association was found between sex and severity of hyponatremia $(\mathrm{p}=0.131)$.

In our study, incidence of hyponatremia was more in male patients $(58.5 \%)$, and no significant difference was observed in duration of hospital stay ( $p$ value $=0.361)$ or outcome $(p$ value $=0.860)$ of the patients based on sex, this finding was not consistent with the study performed by Rao et al., [11] in a study of symptomatic hyponatremia in elderly patients including 100 patients concluded hyponatremia was more common in females and they tend to better tolerate it than their male counterparts. Similary, Sumit Mohan et al., [12] conducted a study on the Prevalence of hyponatremia and association with mortality noted prevalence of hyponatremia was significantly higher in females $(2.09 \%, \mathrm{p}=0.004)$ and increased with age and concluded that hyponatremia is a predictor of mortality in the general population independent of age, gender, and comorbid conditions.

The incidence of hyponatremia is higher in the elderly. This group is more vulnerable mainly owing to impaired ability to maintain water and electrolyte homeostasis in response to dietary and environmental changes. Most of the patients were aged between 41to 50 years $(22.2 \%)$ followed by 51 to 60 years $(16.9 \%)$, 31 to 40 years $(15.8 \%)$ and 61 to 70 years $(15.5 \%)$. Mean age of study population was $38.4 \pm 11.97$ years. Similary, in a study done on frequency and etiology of hyponatremia in adults conducted by Thomas Vurgese et al., [11] the commonest age group affected was 45-64 years. Our findings were not consistent with a study by Rahil AI et al., [8] who reported mean age as $56 \pm 20$ years (range of 17-93 years). Although the range of the age was similar to our study. Mean age was different because the bulk the patients in Rahil AI et al., [8] were elderdy whereas in our study, bulk of the study group was younger.

The clinical presentations of hyponatremia can range from mild non specific symptoms such as headache, and lethargy, to severe symptoms like seizures and coma. In our study commonest symptom reported was lethargy which was present in $50.4 \%$ of the patients. A significant number of patients had headache $(42.3 \%)$ as a presenting complaint. The other presentations included anxiety $(31.7 \%)$, disturbed sleep (18\%), confusion (10.9\%), seizure $(8.8 \%)$ and unresponsiveness $(17.6 \%)$. In a study by Manish Patni et al., [13] from Nagpur, Maharashtra, similar findings were reported with drowsiness as the commonest symptom present in $51 \%$ of the cases, $14 \%$ of patients had vomiting while $6 \%$ patients had seizures. Rao et al., [11] in his study noted that lethargy, drowsiness with slow response and irrelevant talks were most common symptoms. In our study when symptoms were co related with severity of hyponatremia, unresponsiveness was significantly high in patients with severe hyponatremia as compared to moderate hyponatremia (61.7 vs $10.1 \%$; $\mathrm{p}<0.001$ ).

A study by Rahil AI et al., [8] showed CNS involvement in $24.5 \%$ of the patients with symptoms that ranged from confusion to coma. Similarly, in our study, 50 patients had altered sensorium of which 37 $(61.7 \%)$ patients had severe and $13(11.8 \%)$ patients had mild to moderate hyponatremia. Jameela AlSalman et al., [14] in a study concluded that when hyponatremia is accompanied by central nervous system manifestations (hyponatremic encephalopathy), substantial morbidity is seen, whereas asymptomatic hyponatremia is usually benign. Nuket Bayram Kayar et al., [15] in a study of relation between severity of hyponatremia and comorbidity in elderly patients who develop hyponatremia observed a significant relationship between hyponatremia severity and ischemic and congestive heart diseases, neurological disorders, psychiatric disorders and thyroid dysfunction.

\section{CONCLUSION}

Based on the findings of this study it may be concluded that, hyponatremia can present with protean clinical manifestations. The presentation can vary from mild symptoms such as vomiting, lethargy, malaise to severe forms such as confusion, seizure and coma.

\section{REFERENCES}

1. Levin, E. R., Gardner, D. G., \& Samson, W. K. (1998). Natriuretic peptides. New England Journal of Medicine, 339(5), 321-328.

2. Fried, L. F., \& Palevsky, P. M. (1997). Hyponatremia and Hypernatremia. Medical Clinics of North America. 81:585-609.

3. Janicic, N., \& Verbalis, J. G. (2003). Evaluation and management of hypo-osmolality in 
hospitalized patients. Endocrinology and Metabolism Clinics, 32(2), 459-481.

4. Han, D. S., \& Cho, B. S. (2002). Therapeutic approach to hyponatremia. Nephron, 92(Suppl. 1), 9-13.

5. Anderson, R. J. (1986). Hospital-acquired Hyponatremia. Kidney International. 29:1237-47.

6. Fall, P. J. (2000). Hyponatremia and hypernatremia: a systematic approach to causes and their correction. Postgraduate medicine, 107(5), 75-82.

7. Craig, S. (2015). Hyponatraemia. Available from: URL: http:/www.emedicine. com/emerg/topic275.htm. Access date: 28.06.2015.

8. Rahil, A. I., Khan, F. Y., \& Al Badri, M. M. (2009). Clinical profile of hyponatraemia in adult patients admitted to Hamad General Hospital, Qatar: Experience with 53 Cases. J Clin Diag Res, 3, 1419-25.

9. Thomas, C. P., \& Batuman, V. Syndrome of inappropriate antidiuretic hormone secretion. Available from: URL: http://campus.educadium.com/ACS/
10. Hawkins, R. C. (2003). Age and gender as risk factors for hyponatremia and hypernatremia. Clinica chimica acta,337(1-2), 169-172.

11. Rao, M. Y., Sudhir, U., Anil Kumar, T., Saravanan, S., Mahesh, E., \& Punith, K. (2010). Hospital-based descriptive study of symptomatic hyponatremia in elderly patients. $J$ Assoc Physicians India, 58, 667-9.

12. Mohan, S., Gu, S., Parikh, A., \& Radhakrishnan, J. (2013). Prevalence of hyponatremia and association with mortality: results from NHANES. The American journal of medicine, 126(12), 1127-1137.

13. Walmsley, R. N., Watkinson, L. R., \& Koay, E. S. (1992). Cases in chemical pathology: a diagnostic approach. $3^{\text {rd }}$ ed., Singapore: World scientific.

14. Al-Salman, J., Kemp, D., \& Randall, D. (2002). Evidence-based case reviews: hyponatremia. Western journal of medicine, 176(3), 173-176.

15. Kayar, N. B., Kayar, Y., Ekinci, I., Erdem, E. D., \& Ismailova, M. (2016). Relation between severity of hyponatremia and comorbidity in elderly patients who develop hyponatremia. 